\title{
Effects of an iron supplementation trial on the Fe status of Thai schoolchildren
}

\author{
BY PHONGJAN HATHIRAT ${ }^{1}$, AREE VALYASEVI ${ }^{2}$, \\ NITTAYA J. KOTCHABHAKDI ${ }^{1}$, NIPA ROJROONGWASINKUL ${ }^{2}$ \\ AND ERNESTO POLLITT ${ }^{3 *}$ \\ ${ }^{1}$ Department of Pediatrics, Faculty of Medicine, Ramathibodi Hospital, Mahidol University, \\ Bangkok, Thailand \\ ${ }^{2}$ Institute of Nutrition, Mahidol University, Bangkok, Thailand \\ ${ }^{3}$ Department of Pediatrics, School of Medicine and Program of International Nutrition, \\ University of California, Davis, California, USA
}

(Received I November 1990-Accepted I August 199I)

\begin{abstract}
A double-blind clinical trial was conducted among 9- to 11-year-old children in sixteen schools in the Chon Buri province of Thailand to assess the effects of an iron supplement combined with an anthelminthic agent (i.e. albendazole). In addition to the albendazole, $\mathrm{Fe}$ or placebo tablets were distributed to 2268 children enrolled in grades three to five without knowledge of the Fe status of the children. Criteria for case inclusion were: (a) absence of A E Bart's or haemoglobin (Hb) $\mathrm{H}$ disease, (b) absence of abnormal $\mathrm{Hb} \mathrm{EE}$, and (c) age, 108-144 months. The results showed a significant improvement in the Fe status of the children after 16 weeks of treatment. The increments were: $\mathrm{Hb}$ from 124 to $128 \mathrm{~g} / \mathrm{l}$, serum ferritin from 34.54 to $104.72 \mu \mathrm{g} / \mathrm{l}$, transferrin saturation from 24.09 to $35.05 \%$; free erythrocyte protoporphyrin decreased from 444.7 to $281.4 \mu \mathrm{g} / \mathrm{l}$ erythrocytes. These changes were significantly greater than in the control group that received only the anthelminthic agent. However, the administration of albendazole only also resulted in significant changes in the same $\mathrm{Fe}$ indicators.
\end{abstract}

Iron supplementation: Thai schoolchildren

Iron-deficiency anaemia (IDA), a complex public health problem in Thailand, is determined in varying degrees by the interaction of intestinal parasites and low intake and bioavailability of $\mathrm{Fe}$. Among men, the prevalence of anaemia in Thailand has been estimated as twenty-five cases per 100, and among women and children, forty-five cases per 100 (Na-Nakorn, 1979). Vegetables are thought to be the major dietary Fe source (Areekul et al. 1972). Hookworm among schoolchildren in Bangkok and north-east Thailand has ranged from less than $1 \%$ in the city to $90 \%$ in the rural area. An estimated $58 \%$ of the rural children have had a worm infestation resulting in a loss of between 2.7 and $27 \mathrm{ml}$ blood/d through the gastrointestinal tract.

Among the Thai people there is also a high prevalence of haemoglobin $(\mathrm{Hb})$ disorders and heterozygote carrier states (i.e. traits; Na-Nakorn et al. 1956; Wasi et al. 1969). The treatment of anaemia by $\mathrm{Fe}$ in thalassaemia diseases increases the risk of $\mathrm{Fe}$ overload (Weatherall \& Clegg, 1981).

One approach in the treatment of IDA in Thailand has been the fortification of a suitable food item. A fish sauce was, as a condiment, a successful vehicle for $\mathrm{Fe}^{3+}$ EDTA, as observed by the significant changes in the haemotological outcome variables (Garby \& Areekul, 1974). However, the public health benefits derived from its widespread application 
are questionable since some fish sauces are prepared at home and purchased ones are not always fortified with $\mathrm{Fe}$.

An alternative strategy, not devoid of implementation problems, is Fe supplementation. The following report is of a double-blind clinical trial designed to test the effects of an $\mathrm{Fe}$ supplement in the form of ferrous sulphate administered to 9- to 11-year-old children in sixteen schools in the Chon Buri province of Thailand. The treatment also included albendazole, an anthelminthic agent. The $\mathrm{Fe}$ or placebo and the albendazole were distributed without knowledge of the Fe status of the children. In addition to the issue of effectiveness of treatment, the study addressed the following specific questions relevant to public health and policy.

1 Is the risk of Fe deficiency associated with social and economic status?

2 Are there any side effects to an Fe supplementation intervention among schoolchildren with and without Fe deficiency?

3 Is the school an effective delivery system?

4 Is an anthelminthic intervention as effective as an anthelminthic plus $\mathrm{Fe}$ intervention over a 3-month period?

In accordance with the study design, the present paper is restricted to the impact of the treatment on all participants in the study rather than on specific Fe status groups. A complementary analysis to assess the impact of the treatment on school achievement variables has been reported (Pollitt et al. 1989).

\section{METHODS}

Chon Buri is located on the east coast of the Gulf of Thailand. The sixteen schools, each with an enrollment of at least 150 children, were located in non-malarial areas. The schools were approximately $200 \mathrm{~km}$ from Bangkok with good road access. About 2268 children were screened. According to 1980 demographic statistics this number represents about $23 \%$ of the total number of children in the province enrolled in grades three to five (National Statistical Office, 1982). Criteria for case inclusion were: (a) absence of beta thalassaemia A E Bart's or $\mathrm{Hb} \mathrm{H}$ disease, (b) absence of $\mathrm{Hb} \mathrm{EE}$, and (c) age, 108-144 months. A schematic representation of the study design is shown in Fig. 1.

\section{Measurements}

Physical. Every child in the sample received a physical examination before (T1) and after (T2) experimental intervention. Clinical abnormalities such as skin infections, upper respiratory infections, ear infections, or gingivitis due to dental caries were treated and recorded, but the children with such medical problems were included.

Haematology. Venous blood $(15 \mathrm{ml})$ was drawn from the arm and placed into the EDTA tube for blood cell count and determination of thalassaemia-haemoglobinopathies. A drop of blood was placed and sealed with petroleum jelly on a coloured slide stained with Brilliant Cresyl Blue $(10 \mathrm{~g} / \mathrm{l})$ to demonstrate inclusion bodies for alpha-thalassaemia determination. Abnormal $\mathrm{Hb}$ and thalassaemia were determined in every case by $\mathrm{Hb}$ electrophoresis using a cellulose acetate strip (Rigas et al. 1956). If beta-thalassaemia was suspected the diagnosis was confirmed by microcolumn chromatography using DEAESephadex a-50 (Toewsiri, 1977). Any other $\mathrm{Hb}$ abnormalities were confirmed with starch gel electrophoresis (Gammeck et al. 1960). The alpha-thalassaemia trait was determined by the positive inclusion bodies and the percentage of $\mathrm{Hb}$ Bart's which was calculated by solidphase two site immunoradiometric assay (Sanguansermsri et al. 1987).

The methods used for the determination of $\mathrm{Hb}$, packed cell volume, erythrocyte and leucocyte counts, and mean cell volume as well as those for serum Fe, total Fe-binding 


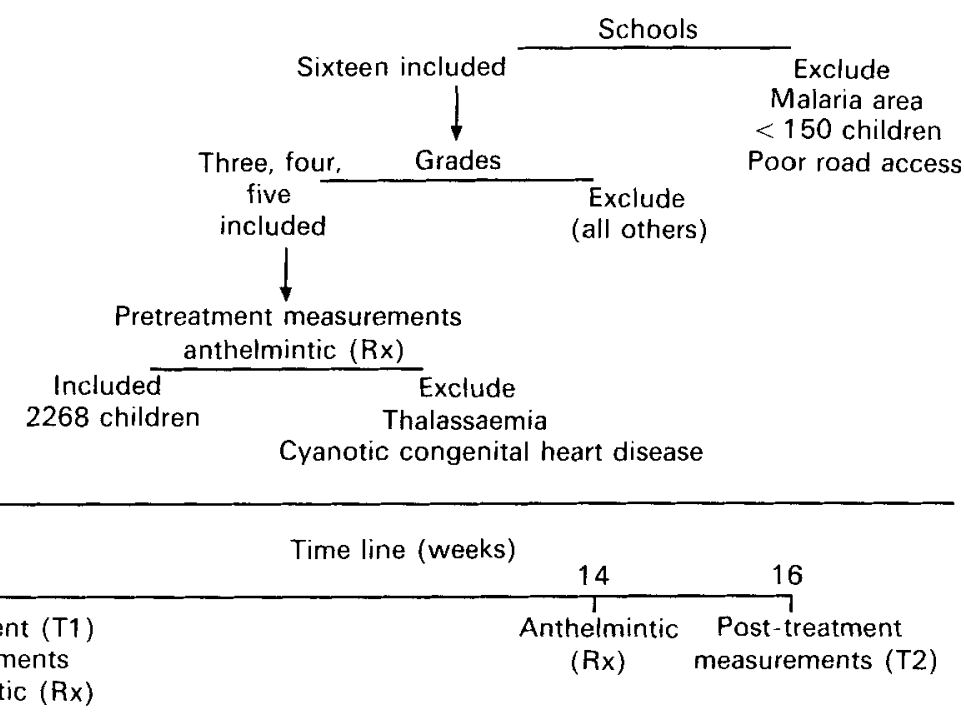

Fig. 1. Schematic representation of experimental design.

capacity, transferrin saturation (TS), serum ferritin (SF) and free erythrocyte protoporphyrin (FEP) have been reported (Pollitt et al. 1989).

At the conclusion of the data collection the sample was reduced to 2171 because of: insufficient or loss of blood sample, error in birth date, emigration or onset of menses.

The most prevalent trait found in the children was $\mathrm{Hb} \mathrm{E}$ at $22.8 \%$ (Table 1 presents the frequency and percentage of the different $\mathrm{Hb}$ traits that were recorded among the subjects enrolled in the study). This value is higher than the average $\mathrm{Hb} \mathrm{E}$ prevalence for the whole country $(13 \%)$ because many of the subjects were children of the north-eastern population whose $\mathrm{Hb} \mathrm{E}$ prevalence is about $50 \%$ (Wasi et al. 1969).

Socio-economic variables. A questionnaire on graduated variables of social structure (e.g. parental occupation, education, income and wealth) was completed by the child with assistance from a parent or adult at the child's residence. In instances where the parents were illiterate the questionnaires were completed with the teacher. Table 2 presents information on wealth, education and occupation for the parents of the children.

\section{Experimental intervention}

The intervention began 2 weeks after the start of the academic year, with $50 \%$ of each grade in each school being randomly placed into an Fe supplement or placebo group before the child's Fe status had been determined. The Fe supplement consisted of one daily tablet of $50 \mathrm{mg} \mathrm{FeSO}$ (about $2 \mathrm{mg} / \mathrm{kg}$ body-weight) for the first 2 weeks, and a $100 \mathrm{mg}$ tablet daily for the remaining 14 weeks. The placebo tablet contained powdered cassava and had a colour, size, and shape similar to the Fe tablet. The tablets were distributed after lunch each day by the teacher. The teacher was uninformed of the type of tablet received by the children. No systematic provision of either tablet was planned for $1 \mathrm{~d}$ school holidays. During the 2 week vacation each child was sent home with tablets and paper to record tablet intake. At least once weekly the teachers who administered the $\mathrm{Fe}$ and placebo tablets asked the children whether they had 'upset stomachs' or other gastric discomforts that could be related to the ingestion of tablets.

Two $200 \mathrm{mg}$ tablets of albendazole, a benzimidazole anthelminthic drug (methyl-5 propylthio-1-H benzimidazole-2-yl carbamate), were given to each student enrolled in the 
Table 1. Frequency and percentage of haemoglobin $(\mathrm{Hb})$ traits in the study sample of Thai schoolchildren (n 2268)

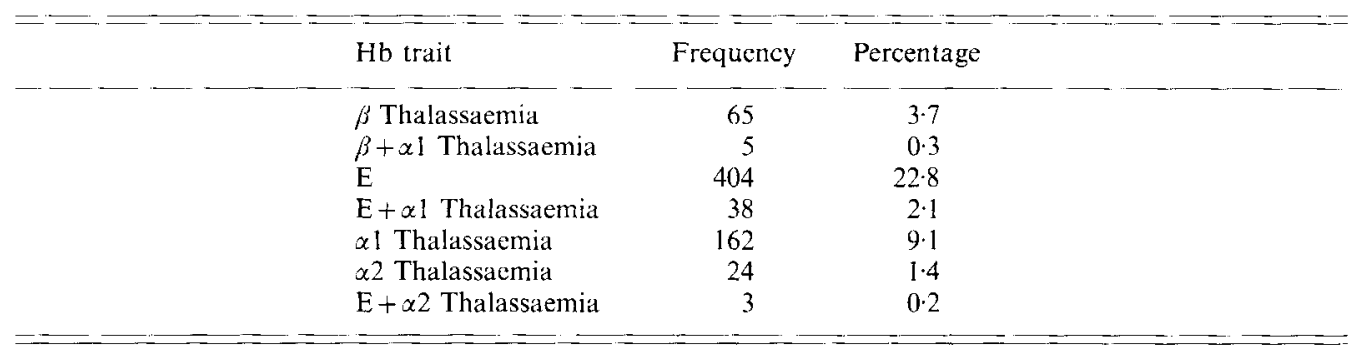

Table 2. Details of social and economic variables of families of the study sample of Thai schoolchildren

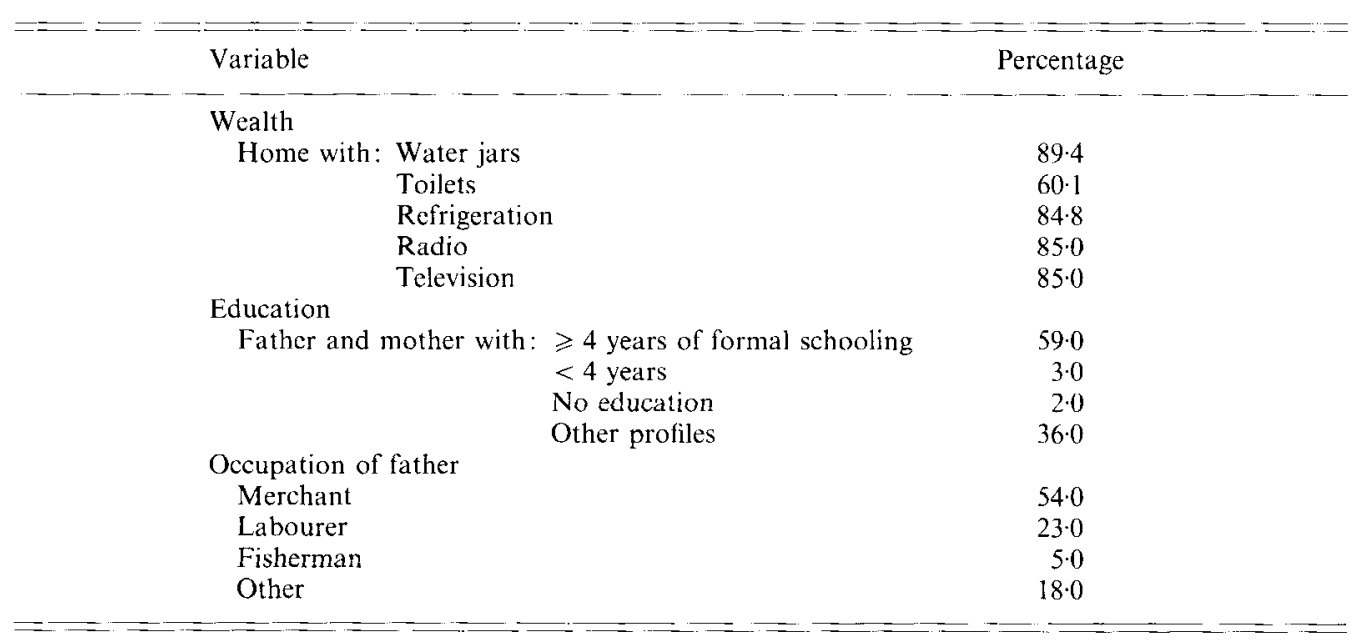

study; one on the day of the blood test at T1, and the other 3 months after the day the iron-placebo intervention was begun (Bogan \& Marriner, 1984; Rossignol, 1984).

Definition of the sample for analysis

To be included in the data analysis the following conditions must have been met in each subject: (a) presence of both a $\mathrm{T} 1$ and a $\mathrm{T} 2 \mathrm{Hb}$ value; (b) not more than one missing value $\mathrm{T} 1$ and T2 of TS, SF or FEP; (c) administration of a daily dose of $2 \mathrm{mg}$ elemental $\mathrm{Fe} / \mathrm{kg}$ initial weight. Since the present study also included an evaluation of the impact of the $\mathrm{Fe}$ treatment on the child's educational achievement as a function of Fe status, the following additional criteria were used for case inclusion: completion of different forms of the same psychoeducational tests at $\mathrm{T} 1$ and $\mathrm{T} 2$ respectively, and a change (T2-T1) in intelligence quotient $<2 \mathrm{sD}$. The sample for data analysis included 1770 subjects.

\section{Statistical consideration of the design}

The first aim of the statistical analysis was to reduce systematic variability. Since the selection of the schools was not random the variation between schools was treated as a systematic source of variation. Another source of systematic variability was the three grade 
Table 3. Iron variables before $(T 1)$ and after experimental intervention with an Fe supplement combined with an anthelminthic $(R x)$ or a placebo $(P l)(T 2)$ : entire sample, children with and without haemoglobin $(H b)$ trait*

\begin{tabular}{|c|c|c|c|c|c|c|c|c|}
\hline & \multicolumn{2}{|c|}{$\mathrm{Hb}(\mathrm{g} / \mathrm{l})$} & \multicolumn{2}{|c|}{$\mathrm{SF}(\mu \mathrm{g} / 1)$} & \multicolumn{2}{|c|}{ TS $(\%)$} & \multicolumn{2}{|c|}{ FEP $(\mu \mathrm{g} / 1)$} \\
\hline & $\mathrm{T} 1$ & $\mathrm{~T} 2$ & $\mathrm{~T} 1$ & $\mathrm{~T} 2$ & $\mathrm{Tl}$ & $\mathrm{T} 2$ & $\mathrm{Tl}$ & $\mathrm{T} 2$ \\
\hline \multicolumn{9}{|c|}{ Entire sample (n 1775) } \\
\hline Rx: Mean & 123 & 128 & $34 \cdot 5$ & $104 \cdot 7$ & $24 \cdot 1$ & $35 \cdot 1$ & 445 & 281 \\
\hline SD & $11 \cdot 0$ & 8.0 & $23 \cdot 2$ & $49 \cdot 3$ & $10 \cdot 1$ & $10 \cdot 5$ & 302 & 119 \\
\hline P1: Mean & 123 & 124 & $36 \cdot 0$ & $41 \cdot 4$ & $23 \cdot 6$ & $28 \cdot 4$ & 438 & 344 \\
\hline so & $11 \cdot 3$ & $9 \cdot 7$ & $24 \cdot 3$ & $26 \cdot 1$ & $9 \cdot 4$ & $10 \cdot 1$ & 298 & 180 \\
\hline \multicolumn{9}{|c|}{ Hb traits excluded ( $n$ 1074) } \\
\hline Rx: Mean & 126 & 130 & $35 \cdot 1$ & $105 \cdot 8$ & $23 \cdot 9$ & 34.9 & 448 & 275 \\
\hline SD & $11 \cdot 1$ & $8 \cdot 0$ & $22 \cdot 9$ & $52 \cdot 2$ & $10 \cdot 2$ & $10 \cdot 8$ & 322 & 116 \\
\hline P1: Mean & 126 & 126 & $36 \cdot 8$ & $42 \cdot 5$ & 23.5 & $28 \cdot 3$ & 443 & 338 \\
\hline SD & $11 \cdot 1$ & $9 \cdot 1$ & $24 \cdot 7$ & $27 \cdot 7$ & 8.8 & 9.6 & 324 & 179 \\
\hline \multicolumn{9}{|c|}{ Hb traits $(n 701)$} \\
\hline Rx: Mean & 120 & 124 & $35 \cdot 5$ & $102 \cdot 5$ & $24 \cdot 2$ & $34 \cdot 8$ & 427 & 290 \\
\hline $\mathrm{SD}$ & $10 \cdot 5$ & $8 \cdot 3$ & $33 \cdot 5$ & 44.9 & $9 \cdot 9$ & $10 \cdot 1$ & 253 & 121 \\
\hline PI: Mean & 119 & 121 & $34 \cdot 7$ & $39 \cdot 7$ & 23.6 & $28 \cdot 6$ & 428 & 353 \\
\hline SO & $11 \cdot 4$ & $9 \cdot 7$ & $23 \cdot 6$ & $23 \cdot 3$ & $10 \cdot 1$ & $10 \cdot 7$ & 252 & 182 \\
\hline
\end{tabular}

$\mathrm{SF}$, serum ferritin $(\mu \mathrm{g} / \mathrm{l})$; TS, transferritin saturation $(\%)$; FEP, free erythrocyte protoporphyrin $(\mu \mathrm{g} / \mathrm{l})$.

* For details of procedures, see pp. 247248 and Fig. 1.

levels. Thus, grades were used as a planned blocking factor. Treatment status (Fe-placebo) was the last planned blocking or between factor in the design. Treatment status was assigned randomly within each grade.

The second aim was to reduce within-group variability. By group we mean the multi-way classification of school by grade and by treatment. The variability within cells and between subjects was removed by using the pre- and post-treatment measurements of an outcome as repeated measurements. Thus, the variability among subjects that is attributable to individual differences is removed from the error variance.

In studies such as this where the research design is unbalanced, the analysis of variance must be subjected to some form of weighing or adjustment which is most commonly performed by using the general linear model statistical routines. In addition, there are cells with very few observations. The sparseness of observations presents a problem of estimation, hence a loss of power. Thus, the design yields an analysis approach that can be summarized as an unbalanced multi-way analysis of variance with repeated measures of one factor (Rossignol, 1984).

\section{RESULTS}

Table 3 presents the $\mathrm{T} 1$ and $\mathrm{T} 2$ means and respective standard deviations for the four $\mathrm{Fe}$ variables of the entire sample classified according to the nature of the intervention. Table 3 also contains the information on the Fe variables of the samples with and without $\mathrm{Hb}$ traits.

\section{Repeated measurements}

$H h$. The between-group analysis yielded a school $(F 4.7 ; P<0.001)$, a grade $(F 16.9$; $P<0.05)$ and treatment $(F 18.9 ; P<0.001)$ effect. There were significant differences between schools in the mean $\mathrm{Hb}$. Also, the mean $\mathrm{Hb}$ of the later grades and of those that 
received $\mathrm{Fe}$ were respectively higher than those of the earlier grades and those that received a placebo. Neither gender nor any of the interactive terms in the between-group analysis were statistically significant.

The within-group analysis showed that the change in the $\mathrm{Hb}$ value from the pre- to the post-treatment evaluation was highly significant $(F 176.8 ; P<0.001)$. However, the twoway interaction between the time variable and treatment status was also statistically significant $(F 77 \cdot 7 ; P<0 \cdot 001)$. The magnitude of the change (T2 $-\mathrm{T} 1)$ was greater in the group treated with $\mathrm{Fe}$ compared with that of the group that received a placebo.

The interactions between time and school $(F 15.5 ; P<0.001)$ and between time and grade $(F 6.8 ; P<0.01)$ were statistically significant. For both school and grades the groups with the lowest mean $\mathrm{T} 1 \mathrm{Hb}$ had the largest change in $\mathrm{Hb}$ independent of treatment. A statistically significant interaction between time and gender $(F 7.0 ; P<0.05)$ was also observed; the change in the girls was greater than that in the boys.

$S F, T S$ and FEP. The results of the analyses of variance with repeated measurements of $\mathrm{SF}, \mathrm{TS}$ and FEP were similar to those of $\mathrm{Hb}$. The main effects of school $(P<0.001)$, grade $(P<0.05)$, and treatment status $(P<0.001)$ were statistically significant in all cases and in agreement with the direction of values for $\mathrm{Hb}$. Further, there were no main effects of gender except in the case of TS $(P<0.001)$.

In the within-group analyses the two-way interaction between time and treatment was statistically significant for all three Fe indicators, pointing out that the effects of Fe plus albendazole were significantly greater than those of albendazole without Fe. Likewise, the interaction between time and school $(P<0.001)$ and between time and grade $(P<0.001)$ were statistically significant for all three Fe indicators.

$H b$ traits. There was a statistically significant difference $(t 11.76 ; P<0.0001)$ between the $\mathrm{T} 1$ mean $\mathrm{Hb}$ values of the children with $(\mathrm{Hb} 119$ (SD 10.1) $\mathrm{g} / \mathrm{l})$ and without $(126(\mathrm{SD} 11 \cdot 1)$ $\mathrm{g} / \mathrm{l}$ ) thalassaemia trait independent of assignment to treatment (Table 3). Conversely, the differences in SF, TS, and FEP were not statistically significant. At T2 the difference between the mean $\mathrm{Hb}$ of the children with $(124 \mathrm{~g} / \mathrm{l})$ and those without $(130 \mathrm{~g} / \mathrm{l}) \mathrm{Hb}$ trait, treated with $\mathrm{Fe}$, was still statistically significant $(t 10.59 ; P<0.0001)$. The T2 betweengroup differences in the other $\mathrm{Fe}$ variables were not statistically significant.

The present focus is on whether the treatment of $\mathrm{Fe}$ in the group of subjects with $\mathrm{Hb}$ trait had effects similar to those observed in the entire sample. The analysis of variance model used is the same as that reported previously. Thus, the effects of school, gender, and sex were calculated, but they have not been reported because they are not relevant to the present discussion.

The time effects on the within-group analysis for $\mathrm{Hb}(F 59 \cdot 74 ; P<0.0001)$, SF $(F 668.27$; $P<0.0001)$, TS $(F 175.2 ; P<0.0001)$, and FEP $(F 231 ; P<0.0001)$ were highly significant. Moreover, the interactive terms of time $\times$ treatment were also significant for $\mathrm{Hb}(F 268$; $P<0.0001)$, SF $(F 525 ; P<0.0001)$, TS $(F 33.1 ; P<0.0001)$ and FEP $(F 22.1 ; P<0.0001)$. These findings on the effects of Fe treatment on the four Fe variables of the subjects with $\mathrm{Hb}$ trait concur in every respect with those for the entire sample.

\section{DISCUSSION}

Effects of $\mathrm{Fe}$-albendazole treatment. The supervised administration in a school setting of about $100 \mathrm{mg} \mathrm{FeSO} / \mathrm{d}$ for $5 \mathrm{~d} /$ week, plus two treatments with $200 \mathrm{mg}$ albendazole over a period of 3 months, resulted in a significant improvement in the Fe status of a population of 9- to 11-year-old children. The increments in Hb, ST, TS, and FEP were significantly greater than those in the control group and demonstrated that, on average, the Fe stores of those treated with $\mathrm{Fe}$ were fully replenished. 
Effects of albendazole. The upward, albeit small, changes in $\mathrm{Hb}, \mathrm{SF}$, and TS and the decline in FEP among the children treated with the anthelminthic agent but without $\mathrm{Fe}$ suggest that administration of the anthelminthic agent alone ameliorated the Fe status of these children. This tentative inference is strengthened by the decline in the number of cases classified as $\mathrm{Fe}$-deficient anaemic and $\mathrm{Fe}$-depleted from $\mathrm{T} 1$ to $\mathrm{T} 2$ among those children who only received albendazole. Based on conventional cut-off criteria for $\mathrm{Hb}(<120 \mathrm{~g} / \mathrm{l})$, SF $(<10 \mu \mathrm{g} / 1)$, TS $(<16 \%)$, and FEP $(>700 \mu \mathrm{g} / 1$ erythrocytes) and for the age-group in question, 7.2 and $2.8 \%$ respectively of the cases where classified as anaemic and $\mathrm{Fe}$ depleted before treatment. After treatment the percentages were 2.8 and 0.5 respectively.

Effects of school and grade. Although the per capita income of the children in the different schools was relatively high (>\$1000 per year) and all schools were in the same province, there was a significant variation in the Fe status of the children across schools. However, there was no association between the distribution of the mean $\mathrm{Hb}$ values of the schools and the geographical distribution of the schools in the province. On the other hand, the mean $\mathrm{Hb}$ for the school was statistically associated with selected indicators of social and economic characteristics of the children in each school. Positive and significant correlations existed between $\mathrm{Hb}$, on the one hand, and the presence of electrical appliances (i.e. radios, refrigerators, television sets; $r 0.72 ; P<0.001)$ and ownership of land $(r 0.60 ; P<0.01)$ on the other. This relationship was also observed with serum ferritin (electrical appliances $r 0.72 ; P<0.001$; ownership of land $r 0.67 ; P<0.01$ ). In the case of TS and FEP these correlations were in the same direction as those of $\mathrm{Hb}$ and SF but did not reach a level of statistical significance. Thus, the schoolchildren with the highest $\mathrm{Fe}$ stores were found in schools located in areas with better economic environments.

Theoretically, the significant effect of grade level on $\mathrm{Hb}$.could be determined by differences in the shape of the $\mathrm{Hb}$ distributions, having a longer tail at the lower end of the distribution in the lower grades. To test such a possibility all cases with $\mathrm{Hb}<120 \mathrm{~g} / \mathrm{l}$ were excluded from the three grades and a one-way analysis of variance was calculated including grade as the independent variable. The mean values across evaluations $((\mathrm{T} 1+\mathrm{T} 2) / 2)$ for the third, fourth, and fifth grade were 128,129 , and $130 \mathrm{~g} / 1$, respectively. This difference was statistically significant $(F 8.53 ; P<0.001)$. Paired comparisons using Scheffe's procedure showed that the mean in the third grade differed from that of the fourth grade which, in turn, differed from that of the fifth grade. Accordingly, the effect of grade seemed to be strictly an effect of age and body-weight on the distribution of $\mathrm{Hb}$ values rather than of any other confounding variable.

Side effects. The children in the Fe-treated group did not report any side effects on the $50 \mathrm{mg} \mathrm{FeSO} / \mathrm{d}$ dose during the first 2 weeks or later on the $100 \mathrm{mg} / \mathrm{d}$ dose for the following 14 weeks. There were also no apparent side effects to albendazole in either group. Other studies in Thailand with pregnant and non-pregnant women have reported side effects to the $\mathrm{Fe}$ treatment such as nausea, vomiting, diarrhoea, or constipation. These effects seemed to have been directly related to the Fe dosage and psychological preparation.

Hb trait. As expected (Na-Nakorn et al. 1956; Wasi et al. 1969), the mean $\mathrm{Hb}$ of the children with $\mathrm{Hb}$ trait was lower and significantly different from that of the children without it. However, the response to the Fe treatment among the former group was similar to that of the latter group. There is no evidence to support the contention that the response of the children without $\mathrm{Hb}$ trait would have been better or higher than those of the children with it, as has been reported in studied with older subjects in Thailand.

The school as an entry point for intervention. The study was presented to the authorities of the educational sector in the province of Chon Buri as a short-term health and nutrition investigation requiring the direct participation of teachers. The authorities were advised that its success depended on close supervision of the teachers' compliance with the 
treatment. The collaboration of the educational authorities and the enthusiastic participation of the school personnel contributed to the success of the therapeutic trial in these schools.

These results contrast with those of one of the two studies reported by Charoenlarp et al. (1988) in Thailand. In that study no changes were observed in the haematological status of Thai schoolchildren following an Fe supplementation trial in school settings, but lack of compliance was the reason for that failure ( $\mathrm{P}$. Charoenlarp, personal communication). Based on the present study, it is concluded that the school is an appropriate vehicle for the delivery of Fe tablets to children, and that the effectiveness of the intervention depends on supervision for compliance.

The critical comments of Drs George Beaton, Jere Haas, Jean-Pierre Habicht and Reynaldo Martorell are gratefully acknowledged. This work was supported by awards from the United Nations University, Tokyo, Japan, and from Hatch Funds ( $\neq$ CA-D*ABS-4625-H) of the University of California, Davis, CA.

\section{REFERENCES}

Areekul, S., Devakul, K., Smitananda, N., Boonyananta, C. \& Klongkumnuangarn, K. (1972). Prevalence of andemia in Thai school children. Journal of the Medical Association of Thailand 55, 457-463.

Bogan, J. A. \& Marriner, S. E. (1984). Pharmacodynamic and toxicological aspects of albendazole in man and animals. In Albendazole in Helminthiasis, Royal Society of Medicine International Congress and Symposium Series no. 61. pp. 13-27 [M. Firth, editor]. London: Royal Society of Medicine.

Charoenlarp, P., Dhanamitta, S., Kaewvichit, R., Silprasert, A., Suwanaradd, C., Na-Nakorn, S., Prawatmuang, P.. Vatanavicharn, S., Nutcharas, U., Pootrakul, P., Tanphaichitr, V., Thanangkul, O., Vaniyapong, T., Toe, Thane, Valyasevi, A., Baker, S., Cook, J., DeMaeyer, E. M. Garby, L. \& Hallberg, L. (1988). A WHO collaborative study on iron supplementation in Burma and in Thailand. American Journal of Clinical Nutrition 47, 280-297.

Gammeck, D. B., Huehns, E. R., Shooter, E. M. \& Gerald, P. S. (1960). Identification of the abnormal polypeptide chain of hemoglobin $\mathrm{G}_{1}$ 6. Journal of Molecular Biology 2, 372-378.

Garby, L. \& AreekuI, S. (1974). Iron supplementation in Thai fish-sauce. The Annual of Tropical Medicine \& Parasitology 68, 467-476.

Na-Nakorn, S. (1979). Deficiency anemia in Thailand. In Proceedings of the Fourth Meeting of the Asian-Pacific Division International Society of Hematology, Seoul, pp. 147-155. Seol: International Society of Haematology.

Na-Nakorn, S., Minnich, V.\& Chernoff, A. I. (1956). Studies on hemoglobin E. II. The incidence of hemoglobin E in Thailand. Journal of Laboratory and Clinical Medicine 47, 490-498.

National Statistical Office (1982). Statistical Reparts of Changwat Chon Buri. Bangkok: Office of the Prime Minister.

Pollitt, E., Hathirat, P., Kotchabhakdi, N. J., Missell, L. \& Valyasevi, A. (1989). Iron deficiency and educational achievement in Thailand. International Conference on Iron Deficiency and Behavioral Development. American Journal of Clinical Nutrition 50, Suppl., 687-697.

Rigas, D. A., Koler, R. D. \& Osgood, E. E. (1956). Hemoglobin H. Journal of Laboratory and Clinical Medicine 47, $51-64$.

Rossignol, J. F. (1984). Double-blind placebo-controlled clinical trial of albendazole: world summary. In Albendazole in Helminthiasis, Royal Society of Medicine International Congress and Symposium Series no. 61. pp. 23-27 [M. Firth, editor]. London: Royal Society of Medicine.

Sanguansermsri, T., Makornkaewkayoo, L. \& Yaemniyom, S. (1987). Diagnosis of alpha-thalassemia trait by mean of solid-phase 2 sites immunoradiometric assay (SPTIRMA) of Hb-Bart's. Presented at the Annual Meeting of the Society of Hematology of Thailand, Bangkok.

Toewsiri, P. (1977). Simple determination of $\mathrm{Hb} \mathrm{A}_{2}$ for detection of heterozygous beta-thalassemia. Bulletin of the Chiangmai Association of Medicine 10, 17-24.

Wasi, P., Na-Nakorn, S. \& Pootrakul, S. (1969). Alpha- and beta-thalassemia in Thailand. Annals of the New York Academy of Sciences 165, 60-82.

Weatherall, D. J. \& Clegg, J. B. (1981). The Thalassemia Syndromes, 3rd ed. Oxford: Blackwell. 